\title{
Brazilian guidelines for diagnosis, treatment and follow-up of primary cutaneous melanoma - Part II*
}

\author{
Luiz Guilherme Martins Castro ${ }^{1,2,3}$ \\ João Pedreira Duprat Neto ${ }^{5}$ \\ Thais Helena Bello Di Giacomo ${ }^{1,2,3}$ \\ Maria Cristina de Lorenzo Messina ${ }^{1,2,3,8}$ \\ Ricardo Silvestre e Silva Macarenco ${ }^{1,10}$ \\ Gabriel Gontijo ${ }^{6}$
}

\author{
Renato Marchiori Bakos ${ }^{4}$ \\ Flávia Vasques Bittencourt ${ }^{6}$ \\ Sérgio Schrader Serpa ${ }^{7}$ \\ Walter Refkalefsky Loureiro ${ }^{9}$ \\ Hamilton Ometto Stolf ${ }^{11}$
}

DOI: http:/ /dx.doi.org/10.1590/abd1806-4841.20164715

\begin{abstract}
The last Brazilian guidelines on melanoma were published in 2002. Development in diagnosis and treatment made updating necessary. The coordinators elaborated ten clinical questions, based on PICO system. A Medline search, according to specific MeSH terms for each of the 10 questions was performed and articles selected were classified from A to D according to level of scientific evidence. Based on the results, recommendations were defined and classified according to scientific strength. The present Guidelines were divided in two parts for editorial and publication reasons. In this second part, the following clinical questions were answered: 1) which patients with primary cutaneous melanoma benefit from sentinel lymph node biopsy? 2) Follow-up with body mapping is indicated for which patients? 3) Is preventive excision of acral nevi beneficious to patients? 4) Is preventive excision of giant congenital nevi beneficious to patients? 5) How should stages 0 and I primary cutaneous melanoma patients be followed?
\end{abstract}

Keywords: Melanoma; Guideline; Diagnostic imaging; Diagnostic techniques and procedures; Sentinel lymph node biopsy; Dermoscopy; Histology

\section{INTRODUCTION}

Cutaneous melanoma $(\mathrm{CM})$ is one of the most potentially dangerous forms accounting for approximately $90 \%$ of deaths of skin cancers. The dermatologist is in the forefront of diagnosis and treatment of CM. It is his/her duty to keep updated on best practices in diagnosis, treatment and disease monitoring to be able to diagnose, treat and council patients in the best way. The last Brazilian guidelines on $\mathrm{CM}$ were published in 2002. ${ }^{1}$ Over 10 years have passed and during this period important advances in the area occurred, with greater relevance to diagnostic techniques. Although some concepts have not changed, it is necessary to update the standards of practice on this important health problem.

These guidelines are intended for diagnostic and therapeutic approach and follow-up of patients with suspected or confirmed diagnoses of primary $\mathrm{CM}(\mathrm{PCM})$ with no clinical nor histological evidence of metastatic disease (stages 0, I and II). They do not include ocular nor mucosal melanoma.

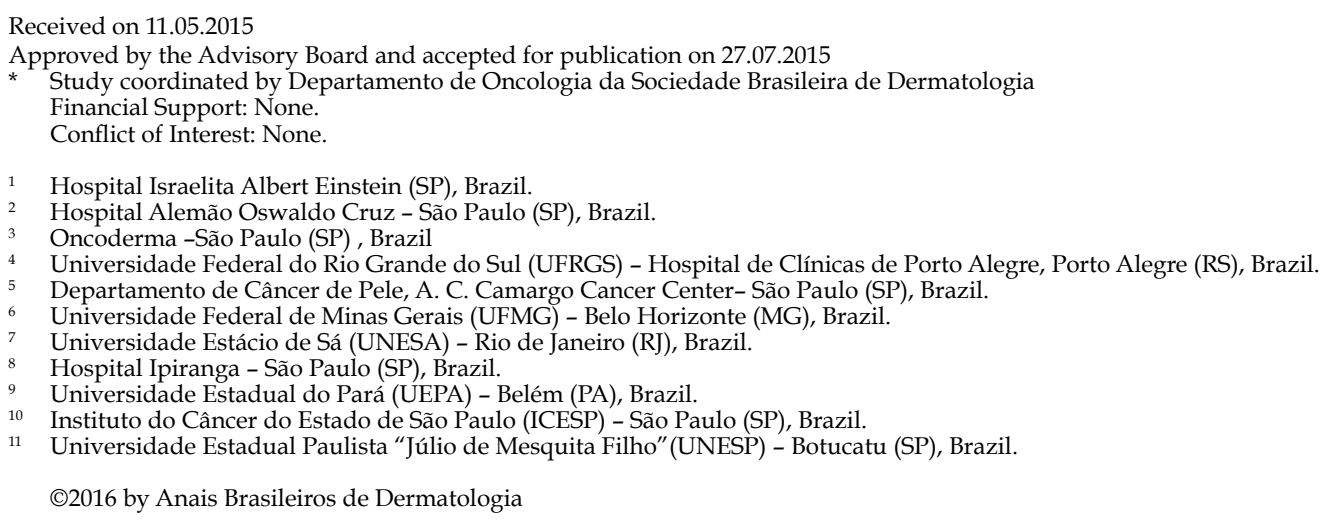




\section{OBJECTIVE}

To introduce the most advanced evidences in diagnosis, therapeutic management and monitoring of PCM clinical stages 0 , I and II patients, describing diagnostic peculiarities that allow identification of these tumors in early stages, as well as measures most widely accepted for treatment and follow-up in the context of Brazilian dermatology.

\section{DESCRIPTION OF EVIDENCE COLLECTION METHOD}

The coordinators have defined 10 questions that reflect issues of clinical relevance on the subject. The questions were structured according to the acronym PICO (patient or population, intervention, comparison or control and outcome), according to regulations of the National Health Agency, the Brazilian Medical Association and Federal Council of Medicine, described in "The process of development, validation and implementation of clinical guidelines in the private healthcare system in Brazil". ${ }^{2}$ To answer these questions, a literature review of scientific articles was conducted in MEDLINE database. Search for evidence was limited primarily to articles published between 01/01/2009 and 06/30/2014 and keywords (MeSH terms) present in the title and/or summary were used, grouped into specific syntaxes for each of the 10 questions alone, as described in table 1.

After reading the abstracts, articles containing information relevant to the subject were selected. When appropriate, references present in these papers were selected, without limit for publication period, and were analyzed using the same methodology as that for the primarily selected studies.

Articles that presented the expected contribution were analyzed regarding the level of evidence (Table 2). Recommendations were written in response to the questions elaborated. Recommendations were also graduated according to level of evidence (Table 2).

\section{RESULTS AND DISCUSSION}

1) Which patients with PCM benefit from performing sentinel lymph node biopsy (SLNB)?

SLNB has been used for melanoma treatment since 1992. At first, it was believed that it could cure
TABLE 2: Grade of recommendation and level of evidence

A: Experimental or observational studies of higher consistency.

B: Experimental or observational studies of lower consistency.

C: Case reports/ uncontrolled studies.

D: Opinion without critical evaluation, based on consensus, physiological studies or animal models.

some cases, as well as reduce morbidity of radical lymphadenectomy that many patients had to undergo. With increased use and outcome of studies devoted to the subject, it was concluded that SLNB does not interfere with survival, but is essential for staging patients with melanoma as well as for regional control (level of evidence A). There are two main advantages in precisely staging the disease: to determine which patients should receive adjuvant therapy and to provide accurate information to the patient about his disease.

A recent study, Multicenter Sentinel Lymph Node Trial-1 (MSLT-1), showed no increase in melanoma-specific survival among patients with PCM with Breslow thickness ranging from 1.2 to $3.5 \mathrm{~mm}$ submitted or not to SLNB. ${ }^{3}$ It was found, however, an increase in disease-free interval for both melanoma patients with intermediate thickness and for patients with thick melanomas (Breslow thickness $>3.5 \mathrm{~mm}$ ). ${ }^{3}$ This study also demonstrated that SLNB is a procedure that properly stages and provides loco regional control, i.e., avoids extensive lymphonodal recurrences, which result in poorer quality of life (level of evidence $\mathrm{A}$ ).

SLNB is also useful for determining which patients may benefit from adjuvant therapy. Adjuvant treatment with pegylated interferon for patients with clinical examination or SLNB-evidenced lymph nodes was evaluated in a prospective, randomized study. ${ }^{4}$ In this initial study there was no improvement in survival with adjuvant therapy. In further data analysis, however, it was observed that patients with SLN compromised by micrometastases and ulcerated primary

TABLE 1: Syntax of descriptors used to research each question and number of selected articles

\begin{tabular}{lll}
\hline Question & Syntax & Number of articles \\
\hline 1 & Sentinel lymph node biopsy AND melanoma & 385 \\
2 & (Follow-up OR monitoring) AND melanoma AND (total body photography or digital dermoscopy) & 49 \\
3 & acral nevus AND melanoma & 150 \\
4 & Congenital nevi AND melanoma & 36 \\
5 & primary melanoma AND follow-up & 94
\end{tabular}


tumor benefited from adjuvant treatment (level of evidence B). ${ }^{5}$

For patients with thin melanomas (Breslow thickness $<1.00 \mathrm{~mm}$ ) positivity levels obtained when performing SLNB are too low to justify indication of the procedure. In cases with thickness ranging from $0.75 \mathrm{~mm}$ to $1.00 \mathrm{~mm}$, positivity is $6 \%$. ${ }^{6}$ In another study, patients with Breslow thickness ranging from $0.75 \mathrm{~mm}$ to $1.00 \mathrm{~mm}$ demonstrated $13 \%$ positivity when ulceration or mitosis were present, or $5 \%$ when these factors were absent. For the group as a whole, positivity was $8 \% .{ }^{7}$ Thus, SLNB can be indicated in rare cases of thin melanoma associated with ulceration and/or lymph vascular invasion (level of evidence B).

There is benefit in using SLNB for melanoma with mitotic index $>1$ and Breslow thickness $>0.75$ $\mathrm{mm}$. For smaller depths, even when mitosis are present, SLNB positivity is $<5 \%$, making SLNB indication questionable (level of evidence B). ${ }^{7}$

For thick melanomas ( $\geq 3.5 \mathrm{~mm}$ ) MSLT-1 study showed benefit in disease-free time and loco regional control (level of evidence B). ${ }^{3}$

Recent studies show that presence of regression alone is not indicative for performing SLNB, since no statistical difference was found when comparing cases with or without regression. ${ }^{7-8}$ The same occurs regarding Clark level ${ }^{8-9}$ (level of evidence B).

\section{Recommendations:}

- SLNB is indicated for patients with PCM with thickness $\geq 1.00 \mathrm{~mm}$, without palpable lymph nodes (grade of recommendation $\mathrm{B}$ ).

- SLNB is indicated for patients with PCM with thickness $<1.00 \mathrm{~mm}$ when ulceration and/or lymph vascular invasion are present (grade of recommendation $B$ ).

- SLNB is indicated for patients with PCM with thickness between $\geq 0.75 \mathrm{~mm}$ and $<1.00 \mathrm{~mm}$ that present one or more mitosis per field (grade of recommendation $\mathrm{B}$ ).

- SLNB is indicated for patients with PCM with thickness $\geq 4.00 \mathrm{~mm}$, for regional control (grade of recommendation $B$ ).

\section{2) Follow-up with body mapping is indicated for which patients?}

Prior to discussion it is essential to clarify the difference between body mapping (BM) and follow-up with $\mathrm{BM}$. BM is the name given to the combination of total body photographic documentation with digital dermoscopy of nevi. ${ }^{10}$ It is indicated for melanoma early diagnosis, and it is based on evaluation of dermoscopic features of the patient's nevi. ${ }^{11,12}$ When used as an isolated test, performed on a single occasion, it works just as a sole dermatoscopic examination, missing one of its major uses: the dynamic observation of the lesions.

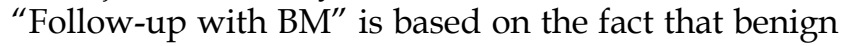
lesions tend to remain stable over time, in contrast to the expected evolution in melanomas. ${ }^{13}$ In addition, follow-up with BM also allows early detection of new lesions, not identified in previous exams. ${ }^{14-16}$

Isolated BM, not aimed at follow-up, is frequently used in Brazil as a diagnostic test to replace/ complement dermoscopic examination usually performed during dermatological consultations. This indication is far from ideal, but is justified in situations where dermoscopy of the entire body surface cannot be performed (level of evidence D).

High-quality publications established parameters for indicating and performing follow-up with BM..$^{10-24}$ Based on epidemiological studies, it was determined that patients who benefit from follow-up with $\mathrm{BM}$ are those who are at increased melanoma risk (level of evidence A). $18,21,22$

Definition of increased melanoma risk is variable. Different studies on the subject mention individual risk factors. The most accepted ones are described in table $3 .{ }^{16-33}$

Indication of follow-up with BM for individuals with moderate to high risk is justified by the greater efficiency of this type of monitoring, which is demonstrated by the lower ratio between excised benign nevi during follow-up of these patients (15:1), compared to 79:1 in low-risk (with no risk factors for melanoma), patients. For low-risk patients follow-up with BM is not indicated because it reduces the specificity of the diagnosis and results in a greater number of unnecessarily excised benign lesions (level of evidence B) ${ }^{34-37}$

TABLE 3: Risk factors most associated with melanoma development

- Presence of atypical nevus syndrome or at least one atypical nevus histologically diagnosed

- Number of melanocytic nevi >50

- Genetic background (if known)

- Personal or family history of melanoma

OTHER RISK FACTORS RELATED TO MELANOMA DEVELOPMENT TO BE CONSIDERED

- Fitzpatrick phototype

- Personal history of non-melanoma skin cancer

- Large number of ephelides

- Hair color (red presents greater risk)

- Light eyes

- History of sunburn in childhood

- History of artificial tanning before 30 years 
Dermoscopic follow-up of isolated lesions (which is different from a BM) with short term revaluation, however, can be used for low-risk patients who have few lesions with some dermoscopic atypia without initial clinical and dermoscopic criteria for melanoma (level of evidence A). In such cases, excision should also be considered as a potentially beneficial alternative to follow-up (level of evidence B). ${ }^{18-35}$

Iatrogenic risk factors, such as immunosuppression or use of vemurafenib, should also be considered when indicating follow-up with BM (level of evidence B). ${ }^{38}$

In addition to defining which patients benefit from follow-up with BM, optimal follow-up regimen was also studied. Two regimens (short and long term follow-up), which have different indications and objectives, are the most accepted. While short term BM follow up is intended to reevaluate few lesions with some degree of suspicion, long term BM follow-up is indicated for multiple unsuspected lesions in individuals with multiple nevi. ${ }^{13,18}$ When suspicious lesions at an early $\mathrm{BM}$ are identified, a revaluation must be re-schedule within 2 to 4 months in order to detect short term dermoscopic changes. This type of monitoring is more precise in identifyng featureless melanomas than the long term BM follow up. It also increases patient adherence ${ }^{39,40}$ (level of evidence A). Patients undergoing short term follow-up with BM where no suspicious lesion was detected should be re-assessed every 6-12 months (level of evidence A). ${ }^{10,13,19,20}$

The combination of short and long term follow-up with BM is indicated because it allows deteciont of a higher proportion of thin and in situ melanomas than that expected in the general population (level of evidence A). ${ }^{13,18,20} \mathrm{~A}$ recent meta-analysis demonstrated a greater melanoma detection probability with longer follow-up..$^{20}$ This fact justifies permanent monitoring, with no expectations of discharge (level of evidence B). ${ }^{13}$

It should be kept in mind that follow-up with BM complements but does not replace clinical and dermoscopic examination of the entire skin surface. High-risk patients followed with BM should also be examined completely periodically by the dermatologist ${ }^{13}$ (level of evidence A).

\section{Recommendations:}

- Follow-up with BM has benefits for patients with increased risk for melanoma (see text) (grade of recommendation A).

Main benefits are:

Fewer excisions of benign lesions, without loss of sensitivity (grade of recommendation A).
Allows diagnosis of thinner melanomas than those diagnosed in individuals not subjected to such follow-up (grade of recommendation A).

- Follow-up with BM is not indicated for low-risk individuals because it reduces diagnostic specificity and results in a greater number of benign lesions unnecessarily excised (grade of recommendation B).

- Isolated suspicious lesions without specific criteria for melanoma, identified in low-risk individuals, can be followed with short term BM, which increases sensitivity for diagnosis of featureless melanoma (grade of recommendation A).

\section{3) Is preventive excision of acral nevi beneficious to patients?}

Acral melanocytic nevi (AMN) often cause concern because it is widely accepted that they would have a higher risk of malignant transformation than those located elsewhere. It is also known that AMN frequently present cytological and architectural atypia, with atypical junctional proliferation on histology ${ }^{41}$ There are no retrospective nor prospective studies indicating the frequency and types of AMN that undergo malignant tranformation. AMN are far from uncommon and acral melanoma (AM) is less common than other types of melanoma. ${ }^{42}$ The opinion among authors ranges from "only remove pigmentary lesions that present irregular shape or color", to "excise every nevus of palmo-plantar region", based on the questionable role of trauma in the development of melanoma in this region. ${ }^{43}$

Relation between presence of AMN and melanoma development in palmo-plantar region is controversial. Rokuhara et al ${ }^{44}$ suggest that this relation is not significant (level of evidence A). Koguchi et al showed that $\mathrm{AMN}$ prevalence in patients who have had plantar AM is not greater than the control group (level of evidence A). ${ }^{45}$ Green et al reported that patients with AM have a large numbers of nevi, including acrally located nevi (level of evidence A). ${ }^{46}$

It is a common belief that risk of developing $\mathrm{AM}$ is greater in African-Americans and Asians. There are publications demonstrating a lower prevalence of AMN in Caucasians compared with African-Americans. Palicka et al found palmar or plantar nevi in $42 \%$ of African-Americans versus $23 \%$ of Caucasians (level of evidence B). ${ }^{47}$ Furthermore, while CM incidence in all sites is significantly higher in Caucasians (level of evidence A) incidence in acral regions is similar between Caucasians and African-Americans ${ }^{48,49}$ (level of evidence B). AM, as a percentage of all melanoma cases, has been reported in $60 \%$ to $75 \%$ of African-American, $43 \%$ to $49 \%$ in Asians, and 5 to $7 \%$ in Caucasians. 
50-52 CM 5-year survival rate is worse in African-Americans compared with Caucasians, but when stratified by stage, prognosis is similar in any race, suggesting that diagnosis in African-Americans tends to be made at more advanced stages. ${ }^{49}$

Few case-control studies are available regarding AM risk factors, which are suspected to differ from those associated with $\mathrm{CM}$ of other sites. UV radiation is thought to play an insignificant role among AM. Green et $\mathrm{al}^{46}$ and Rolon et al ${ }^{53}$ identified prior trauma and presence of preexisting AMN as factors associated with the occurrence of AM (level of evidence A).

Wong et al ${ }^{54}$ and Phan et al ${ }^{55}$ showed $10-27 \%$ histological contiguity between AM and junctional and dermal MN. The authors discuss that these values should demonstrate a downward bias, since AM is usually diagnosed in advanced stages and might destroy the associated nevi (level of evidence B). Furthermore, recent studies suggest that AM can also occur de novo.

Dermoscopy shows different pigment distribution in $\mathrm{AMN}$ and in situ AM, indicating that these lesions arise from different portions of the epidermis and, therefore, would develop independently ${ }^{56,57}$ (level of evidence B). Additionally, a genetic mechanism was proposed for the development of de novo AM, which includes KIT mutation and cyclin D1 gene amplification rather than the previously described BRAF mutation, suggesting that AM did not originate from a nevus ${ }^{58}$ (level of evidence B).

Some authors consider nevi on the genitalia and perianal region as acrally located. As it happens with AMN, preventive removal of nevi in genital and perianal region is common. This is justified by the difficulty in monitoring the lesion, due to the intimate location and reluctance in accepting examination. Hunt et al ${ }^{59}$ performed a retrospective study in children with genital nevi and concluded that preventive biopsy is not necessary in the absence of clinical and dermatoscopic suspicion. The authors found no association between genital nevi and risk factors for melanoma,such as large number of nevi or family history of melanoma (level of evidence B). Gleason et al ${ }^{60}$ performed a clinicopathologic analysis of 56 nevi located on female genitalia and, despite the more frequent presence of histologic features of atypia than in other locations, they followed a benign course (level of evidence B).

\section{Recommendations}

- No studies evaluating the relationship between removal of AMN and benefits for the patient were found.

- There are reports of histologic contiguity between pre-existing AM and AMN. The possibility of AM occuring de novo makes it un- necessary to biopsy every AMN (grade of recommendation $\mathrm{B}$ ).

- Recommendation for preventive resection of AMN on the genitalia and perianal region should follow the same approach of melanoma cases located in other sites, i.e., removal of lesions with clinical or dermatoscopic suspicion (grade of recommendation $\mathrm{C}$ ).

\section{4) Is preventive excision of congenital melanocyt- ic nevi (CMN) beneficious to patients?}

The concern with $\mathrm{CMN}$ is justified by the risk of malignant transformation that it may present. It is known that the risk is proportional to the dimensions of the CMN, what makes the classification of lesions according to size to assume practical importance. The most accepted classification is the one that considers the largest diameter reached by $\mathrm{CMN}$ in adulthood: small $<1.5 \mathrm{~cm}$; medium $=1.5-19.9 \mathrm{~cm}$; and giant $>20.0$ $\mathrm{cm}$. ${ }^{61}$ Considering that nevus growth is proportional to the child's body, it can be estimated that a nevus on the head or the body of a newborn of $>9 \mathrm{~cm}$ and $>6 \mathrm{~cm}$, respectively, will be giant in adulthood. ${ }^{62,63}$

The risk of malignant transformation was overestimated for some time. Giant CMN (G-CMN) present a probable risk throughout life of $<5 \%{ }^{64-66}$ (level of evidence B). On the contrary small or medium CMN (S/M-CMN) present a low risk of melanoma development, close to that observed for general population ${ }^{67,68}$ (level of evidence C). Thus, malignization risk, even for G-CMN, is not so high to make prophylactic excision of these lesions mandatory and dogmatic.

Classically, melanoma risk in G-CMN is referred as higher in the first years of life, when monitoring should be more rigorous. In $55 \%$ of patients with G-CMN who develop melanoma, tumor appears in the first five years of life and $70 \%$ before puberty ${ }^{69,70}$ (level of evidence B). Evidences in the literature are insufficient for safe, consensual recommendation, either for preventive removal of these lesions, or for expectant management (level of evidence A). ${ }^{64,65,67,71-74}$

Studies about S/M-CMN are much more scarce and full of methodological challenges, also leading to inaccurate risk of melanoma, but close to the risk of the general population. In these cases the risk is apparently higher after puberty, since S/M-CMN associated melanoma tends to occur commonly in adulthood ${ }^{75}$ (level of evidence C). Furthermore, melanoma tends to be more superficial, (origin at the dermo-epidermal junction), which may facilitate its detection, and occurs preferably at the periphery of nevus (level of evidence C). ${ }^{75-78}$

G-CMN associated melanoma can have a deeper origin in the skin (dermis), presenting as a tumor or nodule. The presence of these, especially if firm, hard- 
ened and adherent, with fast growth history, associated or not with adenopathy, should be observed with caution. If that is the case, performing a biopsy should be considered. Neuroid tumors, such as neurofibromas and schwannomas, common in G-CMN, generally present elastic and movable consistency. Palpation of skin and lymph node chain is an essential step of the physical examination of these patients.

Apparently, G-CMN lesions that carry increased risk of malignancy are those located in the axis (trunk, head/neck), especially the large ones $(>40 \mathrm{~cm})$ with numerous satellite lesions. ${ }^{79}$ Approximatively $75 \%$ of G-CMN associated melanomas occur in nevi with "bathing suit" distribution. ${ }^{74,75}$ Moreover, nevus restricted to limbs present reduced risk of malignancy, as well as those in individuals with few satellite lesions. The malignant transformation of satellites lesions (found in $80 \%$ of patients with G-CMN) is improbable. Clinical significance of satellite lesions is to translate increased risk of neurological involvement (Neurocutaneous melanosis - NCM) and melanoma, when present in large numbers $(>50)$.

Paradoxically, G-CMN lesions with higher risk of melanoma, which removal could theoretically be beneficial, are difficult to excise, either because of nevus dimension, which can compromise a significant area of the tegument, or because nevus cells are located deeper into the skin, sometimes reaching the muscular fascia.

It must be remembered that melanoma risk is not limited to the skin or nevi, but may also occur in extra-cutaneous sites, especially in the central nervous system. In such case, it is refered to as neuro-cutaneous melanosis (NCM), defined as melanocytic proliferation of benign or malignant lesions in the leptomeninges, most commonly associated with G-CMN. Thus, complete removal of G-CMN does not stop the risk of melanoma, because it is unfeasible to remove all nevus cells in extra-cutaneous sites.

Management of CMN should be individualized and discussed with the patient and family, considering, in addition to melanoma risk, other aspects such as age, location of the nevus, size and depth, clinical appearence (especially color and surface), personal and family risk of melanoma, aesthetic impact and patient's desire or not to remove the nevus (level of evidence B). $63,64,66,68,71$

\section{Recommendations}

\section{a) Small or medium CMN}

- There is no dogmatic approach. As well as melanoma risk, factors such as age, location (especially in difficult self-examination areas), size, clinical and dermoscopic appearance of the nevus, history of modification, presence of other risk factors for melanoma, aesthetic impact and patient desire must be taken into consideration (grade of recommendation A).

- When surgical excision is the option, it is should preferably be performed from 7-8 years until puberty, when the child already collaborates with the procedure under local anesthesia (grade of recommendation C).

- Photographic monitoring and digital dermoscopic evaluation (especially of smaller nevi) are very useful in the clinical management of these patients (grade of recommendation C).

\section{b) Giant CMN}

- G-CMN removal, when desired and feasible, must be early, since the risk of melanoma is apparently greater in childhood (grade of recommendation B).

- When indicated, intervention should be performed after the first six months of life due to the risk of anesthetic complications in this age group (grade of recommendation C).

- Although the risk is apparently higher in childhood and adolescence, it is advisable to keep track during adulthood, because the risk remains throughout life (grade of recommendation B).

- Patients with NCM do not benefit from excision of the nevus (grade of recommendation B).

- The approach of the G-CMN should be multidisciplinary (dermatologists, pediatricians, plastic surgeons, neurologists and psychologists, among other professionals) and individualized for each patient (grade of recommendation B).

- Histologic interpretation of G-CMN associated nodes (especially in children $<1$ year) should be performed by experienced dermatopathologists since they often simulate melanoma (grade of recommendation B).

\section{5) How should stages 0 and I primary cutaneous melanoma patients be followed?}

The potential aggressiveness of $\mathrm{CM}$ justifies the follow-up of patients after completion of necessary therapeutic measures. The main objectives of follow-up are two: to reduce morbidity and mortality through early detection of disease progression and to search for new primary lesions. Every patient diagnosed with CM should be staged according to the recommendations of the American Joint Committee on Cancer (7th edition) (level of evidence A). ${ }^{80}$

In stage I are included patients with invasive melanoma and Breslow thickness $<1.0 \mathrm{~mm}$ (T1), as well as patients with melanomas and Breslow thickness $1,1 \mathrm{~mm}$ to $2.0 \mathrm{~mm}$, but not exhibiting ulceration 
or positive mitotic index (T2a). Stage 0 corresponds to patients with in situ melanoma .

Patients diagnosed with stage I PCM have less chance of relapse compared with more advanced stages. Patients with T1 and T2 tumors present 10-year survival rates of $92 \%$ and $80 \%$, respectively. For stage 0 patients the survival rate is almost $100 \% .{ }^{80}$

Soon after diagnosis a careful history should be taken (clinical history and physical examination), followed by guidance on melanoma and its potential consequences. Furthermore, an adequate level of understanding on the aspects of the disease must be acquired by patients and a constant dialogue, accessible and understandable to their level of knowledge, must be offered during the period of follow-up, clarifying issues related to the disease. Appropriate orientation regarding the possibility of relapse or appearance of new primary lesions, social issues and primary preventive care for individuals and their families should also be given. (level of evidence D). ${ }^{81-83}$

Patients with stage II PCM should conduct periodic clinical examination, consisting of general skin assessment and palpation of lymph nodes. There is no consensus on the frequency of this assessment. Recommendations are that it should be performed 2-4 times a year during the first 5 years after diagnosis and once a year until completing 10 years of follow-up. Frequency may depend on factors such as presence of multiple primary melanomas (MPM), atypical nevi, family history, patient anxiety and ability to recognize recurrences or new lesions (evidence level D). ${ }^{8,82-84} \mathrm{In}$ more than half of patients with relapses, lesions are detected by the patients themselves, thus they should be taught to perform self-examination of the skin and lymphatic chains in search of suspicious lesions (level of evidence C). ${ }^{82,85-87}$

Patients in stage 0 apparently do not require periodic clinical examination, since disease progression is unlikely (level of evidence C). ${ }^{22,86}$ The possibility of MPM must be taken into consideration for such patients, therefore stage 0 PCM patients should receive information and perform self-examination of the skin and general examination of skin annually (level of evidence D).

Although some authors indicate laboratory tests (especially serum lactate dehydrogenase and alkaline phosphatase), the majority suggests that such exams should not be performed routinely in patients in stage I (level of evidence C). ${ }^{8,22,81-83,88}$ S100 serum levels was observed as a potential predictor of advanced disease in patients with CM. Patients with stage I to III can present it as a progression marker. In places where S100serum levels is available, the recommendation is to use it. Patients with stage 0 do not need to perform additional tests (level of evidence C). ${ }^{22,86,88,89}$
There is little evidence of benefits in performing imaging exams for stage I PCM patients. Chest X-ray appears not to provide benefits when performed in routine. It may identify false-positive lesions, presenting low possibility of detection of lesions with surgical potential to modify survival, besides not being able to diagnose early lung metastases. Sometimes it causes anxiety in patients. Patients with stage 0 do not require imaging (level of evidence C). ${ }^{90-93}$

Abdominal ultrasound (US) is also not routinely recommended for asymptomatic stage I PCM patients. Cost-effectiveness is low for metastases detection in this group of patients (level of evidence C). ${ }^{89-92}$ Axillary and inguinal US-proven lymph-nodes, in some studies, to be superior to palpation in the detection of metastases. Thus, its use may be indicated for this group of patients, especially those with $\mathrm{Ib}$ or thicker tumors, always considering the cost-effectiveness and availability of the method, as well as the ability of professionals to perform it (level of evidence C). ${ }^{22,86,94-}$ ${ }^{97}$ CT scan also presents little benefit for patients with thin $\mathrm{CM}$, adding significant rates of radiation exposure ${ }^{98}$ (level of evidence C). It's use should be restricted for patients with suspicion of recurrence based on clinical and/or imaging examination conducted with a less accurate method (level of Evidence D).

PET scan seems to have higher resolution to detect suspicious lesions, but given the low probability of disease progression in stages 0 and I, the vast majority of tests conducted in patients with early $\mathrm{CM}$ are normal, and false positives may occur; thus this examination is not recommended on a routine basis ${ }^{99}$ (level of evidence C).

Finally, most authors suggest that complementary and imaging tests should be performed only in patients with stage I PCM who are symptomatic and present suspicion of tumor recurrence on physical examination (level of evidence D). ${ }^{8,22,81-83}$

\section{Recommendations:}

- All patients diagnosed with melanoma should be evaluated clinically and staged according to the AJCC TNM system (grade of recommendation $\mathrm{A}$ ).

- Stage 0 melanoma patients do not need follow-up with laboratory or imaging tests (grade of recommendation C).

- Stage II melanoma patients should perform clinical evaluation of the skin and lymph nodes regularly (2-4 times a year) in the first 5 years after diagnosis of melanoma and once a year until completing 10 years of follow-up (grade of recommendation D).

- Laboratory and imaging tests should be performed only for patients with stage I mela- 
noma who present symptomatic or suspicion of disease recurrence, according to the physician's choice and tests availability (grade of recommendation C).

- US of lymph node chains (level of evidence C) and dosage of S100 serum levels may be valid, even in asymptomatic patients, if they present stage $\mathrm{Ib}$ or higher, and according to the availability and accessibility of the method (grade of recommendation C).

At the end of the presentation of this second part of the Brazilian guidelines on melanoma, it is very important to highlight that these guidelines are not intended to restrain medical practice, but make it more homogeneous, reducing uncertainty/disagreement of good practice standards. By establishing standards, in addition to reducing the differences in care, it is also possible to provide options based on evidence, allowing the physician to make decisions about treatment or diagnostic methods, reducing the strain on patients, doctors and health system.

These guidelines reflect the best scientific information published on the subject until the date of its preparation. Nevertheless, these data must be interpreted carefully, since the results of future studies could lead to changes in recommendations. In some cases, these guidelines should not be followed, always keeping in mind the patient's well being as well as other special circumstances. It is also important to remember that it is out of the scope of these guidelines to discuss aspects of prevention of skin cancers, such as use of sunscreen and other measures, which should be discussed in a specific article.]

\section{Acknowledgements}

To Rosalyn Leite and the library staff of the Sociedade Brasileira de Dermatologia, coordinated by the librarian Vanessa Zampier.

\section{REFERENCES}

1. Tovo FLR, Belfort FA, Sanches Jr JA. Melanoma cutâneo - Abordagem da lesão primária. Acta Oncol Bras. 2003;23:454-8.

2. Agencia Nacional de Saúde Suplementar. Associação Medica Brasileira. Conselho Federal de Medicina 0 processo de elaboração, validação e implementação das diretrizes clinicas na saúde suplementar no Brasil. Rio de Janeiro: ANS; 2009. 78 p.

3. Morton DL, Thompson JF, Cochran AJ, Mozzillo N, Nieweg OE, Roses DF, et al. Final trial report of sentinel-node biopsy versus nodal observation in melanoma. $\mathrm{N}$ Engl J Med. 2014;370:599-609.

4. Eggermont AM, Suciu S, Santinami M, Testori A, Kruit WH, Marsden J, et al. Adjuvant therapy with pegylated interferon alfa-2b versus observation alone in resected stage III melanoma: final results of EORTC 18991, a randomised phase III trial. Lancet. 2008;372:117-26.

5. Eggermont AM, Suciu S, Testori A, Santinami M, Kruit WH, Marsden J, et al. Long term results of the randomized phase III trial EORTC 18991 of adjuvant therapy with pegylated interferon alfa- $2 \mathrm{~b}$ versus observation in resected stage III melanoma. J Clin Oncol. 2012;30:3810-8.

6. Andtbacka $\mathrm{RH}$, Gershenwald JE. Role of sentinela lymph node biopsy in patients with thin melanoma. J Natl Compr Canc Netw. 2009;7:308-17.

7. Han D, Yu D, Zhao X, Marzban SS, Messina JL, Gonzalez RJ, et al. Sentine node biopsy is indicated for thin melanomas $\geq 0,76 \mathrm{~mm}$. Ann Surg Oncol. 2012;19:3335-42.

8. Coit DG, Andtbacka R, Anker CJ, Bichakjian CK, Carson WE 3rd, Daud A, et al. National Comprehensive Cancer Network (NCCN). Melanoma, version 2.2013: featured updates to the NCCN guidelines. J Natl Compr Canc Netw. 2013;11:395407.

9. White RL Jr, Ayers GD, Stell VH, Ding S, Gershenwald JE, Salo JC, et al. Factors predictive of status of sentinel lymph nodes in melanoma patients from a large multicenter database. Ann Surg Oncol. 2011;18:3593-600.

10. Salerni G, Carrera C, Lovatto L, Puig-Butille JA, Badenas C, Plana E,et al. Benefits of total body photography and digital dermatoscopy ("two-step method of digital follow-up") in the early diagnosis of melanoma in patients at high risk for melanoma. J Am Acad Dermatol. 2012;67:e17-27.

11. Haenssle HA, Krueger U, Vente C, Thoms KM, Bertsch HP, Zutt M, et al. Results from an observational trial: digital epiluminescence microscopy follow-up of atypical nevi increases the sensitivity and the chance of success of conventional dermoscopy in detecting melanoma. J Invest Dermatol. 2006;126:980-5.
12. Salerni G, Carrera C, Lovatto L, Martí-Laborda RM, Isern G, Palou J, et al. Characterization of 1152 lesions excised over 10 years using total-body photography and digital dermatoscopy in the surveillance of patients at high risk for melanoma. J Am Acad Dermatol. 2012;67:836-45.

13. Puig S, Malvehy J. Monitoring patients with multiple nevi. Dermatol Clin. 2013;31:565-77, viii.

14. Banky JP, Kelly JW, English DR, Yeatman JM, Dowling JP. Incidence of new and changed nevi and melanomas detected using baseline images and dermoscopy in patients at high risk for melanoma. Arch Dermatol. 2005;141:998-1006.

15. Kittler $\mathrm{H}$, Pehamberger $\mathrm{H}$, Wolff $\mathrm{K}$, Binder M. Follow-up of melanocytic skin lesions with digital epiluminescence microscopy: patterns of modifications observed in early melanoma, atypical nevi, and common nevi. J Am Acad Dermatol. 2000;43:467-76.

16. Kittler H, Guitera P, Riedl E, Avramidis M, Teban L, Fiebiger M, et al. Identification of clinically featureless incipient melanoma using sequential dermoscopy imaging. Arch Dermatol. 2006;142:1113-9.

17. Menzies SW. Evidence-based dermoscopy. Dermatol Clin. 2013;31:521-4, vii.

18. Argenziano G, Giacomel J, Zalaudek I, Blum A, Braun RP, Cabo H, et al. A clinicodermoscopic approach for skin cancer screening: recommendations involving a survey of the International Dermoscopy Society. Dermatol Clin. 2013;31:525-34, vii.

19. Terushkin V, Dusza SW, Scope A, Argenziano G, Bahadoran P, Cowell L, et al. Changes observed in slow-growing melanomas during long term dermoscopic monitoring. Br J Dermatol. 2012;166:1213-20.

20. Salerni G, Terán T, Puig S, Malvehy J, Zalaudek I, Argenziano G, et al. Metaanalysis of digital dermoscopy follow-up of melanocytic skin lesions: a study on behalf of the International Dermoscopy Society. J Eur Acad Dermatol Venereol. 2013;27:805-14.

21. Cancer Council Australia., Ministry of Health.; Melanoma Network (N.S.W.); Cancer Institute NSW., New Zealand Guidelines Group. Clinical Practice Guidelines for the Management of Melanoma in Australia and New Zealand: Evidence-based Best Practice Guidelines. Sydney, N.S.W. : Cancer Council Australia: Ministry of Health, 2008.

22. Marsden JR, Newton-Bishop JA, Burrows L, Cook M, Corrie PG, Cox NH, et al. Revised U.K. guidelines for the management of cutaneous melanoma 2010. Br J Dermatol. 2010;163:238-56. 
23. Gulia A, Massone C. Advances in dermoscopy for detecting melanocytic lesions. F1000 Med Rep. 2012;4:11.

24. Argenziano G, Catricalà C, Ardigo M, Buccini P, De Simone P, Eibenschutz $L$, et al. Dermoscopy of patients with multiple nevi: improved management recommendations using a comparative diagnostic approach. Arch Dermatol. 2011;147:46-9.

25. Rhodes AR, Weinstock MA, Fitzpatrick TB, Mihm MC Jr, Sober AJ. Risk factors for cutaneous melanoma. A practical method of recognizing predisposed individuals. JAMA. 1987;258:3146-54.

26. Vuong K, McGeechan K, Armstrong BK, Cust AE. Risk prediction models for incident primary cutaneous melanoma: a systematic review. JAMA Dermatol. 2014; $150: 434-44$

27. Rhodes AR. Public education and cancer of the skin. What do people need to know about melanoma and nonmelanoma skin cancer? Cancer. 1995;75:613-36.

28. Gandini S, Sera F, Cattaruzza MS, Pasquini P, Zanetti R, Masini C, et al. Metaanalysis of risk factors for cutaneous melanoma, III: family history, actinic damage and phenotypic factors. Eur J Cancer. 2005;41:2040-59.

29. Gandini S, Sera F, Cattaruzza MS, Pasquini P, Picconi 0, Boyle P, et al. Metaanalysis of risk factors for cutaneous melanoma, II: sun exposure. Eur J Cancer. 2005:41:45-60.

30. Gandini S, Sera F, Cattaruzza MS, Pasquini P, Picconi 0, Boyle P, et al. Metaanalysis of risk factors for cutaneous melanoma, I: common and atypical naevi. Eur J Cancer. 2005;41:28-44.

31. van der Rhee Jl, Bergman W, Kukutsch NA. Impact of dermoscopy on the management of high-risk patients from melanoma families: a prospective study. Acta Derm Venereol. 2011;91:428-31.

32. Greene MH, Clark WH Jr, Tucker MA, Kraemer KH, Elder DE, Fraser MC. High risk of malignant melanoma in melanoma-prone families with dysplastic nevi. Ann Intern Med. 1985;102:458-65.

33. Marghoob AA, Kopf AW, Rigel DS, Bart RS, Friedman RJ, Yadav S, et al. Risk of cutaneous malignant melanoma in patients with "classic" atypical-mole syndrome. A case-control study. Arch Dermatol. 1994;130:993-8.

34. Schiffner R, Schiffner-Rohe J, Landthaler M, Stolz W. Long term dermoscopic follow-up of melanocytic naevi: clinical outcome and patient compliance. $\mathrm{Br} \mathrm{J}$ Dermatol. 2003;149:79-86.

35. Haenssle HA, Korpas B, Hansen-Hagge C, Buhl T, Kaune KM, Johnsen S, et al. Selection of patients for long term surveillance with digital dermoscopy by assessment of melanoma risk factors. Arch Dermatol. 2010;146:257-64.

36. Tromme I, Sacré L, Hammouch F, Legrand C, Marot L, Vereecken P, et al. Availability of digital dermoscopy in daily practice dramatically reduces the number of excised melanocytic lesions: results from an observational study. $\mathrm{Br}$ J Dermatol. 2012;167:778-86.

37. Menzies SW, Emery J, Staples M, Davies S, McAvoy B, Fletcher J, et al. Impact of dermoscopy and short term sequential digital dermoscopy imaging for the management of pigmented lesions in primary care: a sequential intervention trial. Br J Dermatol. 2009;161:1270-7.

38. Perier-Muzet M, Thomas L, Poulalhon N, Debarbieux S, Bringuier PP, Duru G, et al . Melanoma Patients under Vemurafenib: Prospective Follow-Up of Melanocytic Lesions by Digital Dermoscopy. J Invest Dermatol. 2014;134:1351-8.

39. Argenziano G, Mordente I, Ferrara G, Sgambato A, Annese P, Zalaudek I. Dermoscopic monitoring of melanocytic skin lesions: clinical outcome and patient compliance vary according to follow-up protocols. Br J Dermatol. 2008;159:331-6.

40. Altamura D, Avramidis M, Menzies SW. Assessment of the optimal interval for and sensitivity of short term sequential digital dermoscopy monitoring for the diagnosis of mela- noma. Arch Dermatol. 2008;144:502-6.

41. Evans MJ, Gray ES, Blessing K. Histopathological features of acral melanocytic nevi in children: study of 21 cases. Pediatr Dev Pathol. 1998;1:388-92.

42. Cullen SI. Incidence of nevi. Report of survey of the palms, soles, and genitalia of 10,000 young men. Arch Dermatol. 1962;86:40-3.

43. Gorelick MF. Guidelines for removal of acral and mucosal nevi. J Am Acad Dermatol. 1980;3:206-7.

44. Rokuhara S, Saida T, Oguchi M, Matsumoto K, Murase S, Oguchi S. Number of acquired melanocytic nevi in patients with melanoma and control subjects in Japan. J Am Acad Dermatol. 2004;50:695-700.

45. Kogushi-Nishi H, Kawasaki J, Kageshita T, Ishihara T, Ihn H. The prevalence of melanocytic nevi on the soles in the japanese population. J Am Acad Dermatol. 2009;60:767-71.

46. Green A, McCredie M, MacKie R, Giles G, Young P, Morton C, et al. A case-control study of melanomas of the soles and palms (Australia and Scotland). Cancer Causes Control. 1999;10:21-5.

47. Palicka GA, Rhodes AR. Acral Melanocytic Nevi. Prevalence and distribution of gross morphologic features in White and black adults. Arch Dermatol. 2010;146:1085-94.

48. Seer.cancer.gov [Internet]. Altekruse SF, Kosary CL, Krapcho M. National Cancer
Institute. SEER Cancer Statistics Review, 1975-2007. [cited 2015 Jan 5]. http:// seer.cancer.gov/csr/1975_2007/.

49. Stevens NG, Liff JM, Weiss NS. Plantar melanoma: is the incidence of melanoma of the sole of the foot really higher in blacks than whites? Int J Cancer. 1990;45:691-3.

50. Hudson DA, Krige JE. Melanoma in black South Africans. J Am Coll Surg 1995; 180:65-71.

51. Seiji M, Takematsu H, Hosokawa M, Obata M, Tomita $\mathrm{Y}$, Kato T, et al. Acral melanoma in Japan. $J$ Invest Dermatol. 1983;80:56s-60s.

52. Kuchelmeister C, Schaumburg-Lever G, Garbe C. Acral cutaneous melanoma in caucasians: clinical features,histhopathology and prognosis in 112 patientes. $\mathrm{Br} \mathrm{J}$ Dermatol. 2000;143:275-80.

53. Rolón PA, Kramárová E, Rolón HI, Khlat M, Parkin DM. Plantar melanoma: a casecontrol study in Paraguay. Cancer Causes Control. 1997;8:850-6.

54. Wong TY, Ohara K, Kawashima M, Sober AJ, Nogita T, Mihm MC Jr. Acral lentiginoua melanoma (including in situ melanoma) arising in association with naevocellular nevi. Melanoma Res. 1996;6:241-6.

55. Phan A, Touzet S, Dalle S, Ronger-Savlé S, Balme B, Thomas L. Acral lentiginous melanoma: histopathological prognostic features of 121 cases. Br J Dermatol. 2007;157:311-8.

56. Saida T, Koga H, Goto Y, Uhara H. Characteristic distribution of melanin columns in the cornified layer of acquired acral nevus: an important clue for histopathologic differentiation from early acral melanoma. Am J Dermatopathol. 2011;33:468-73.

57. Saida T, Koga H, Uhara H. Key points in dermoscopic differentiation between early acral melanoma and acral nevus. J Dermatol. 2011;38:25-34.

58. Takata M, Murata H, Saida T. Molecular pathogenesis of malignant melanoma: a different perspective from the studies of melanocytic nevus and acral melanoma. Pigment Cell Melanoma Res. 2010;23:64-71.

59. Hunt RD, Orlow SJ, Schaffer JV. Genital melanocytic nevi in children: experience in a pediatric dermatology practice. J Am Acad Dermatol. 2014;70:429-34.

60. Gleason BC, Hirsch MS, Nucci MR, Schmidt BA, Zembowicz A, Mihm MC Jr, et al. Atypical genital nevi. A clinicopathologic analysis of 56 cases. Am J Surg Pathol. 2008;32:51-7.

61. Kopf AW, Bart RS, Hennessey P. Congenital nevocytic nevi and malignant melanomas. J Am Acad Dermatol. 1979;1:123-30.

62. Makkar HS, Frieden IJ. Neurocutaneous melanosis. Semin Cutan Med Surg. 2004;23:138-44.

63. Marghoob AA, Borrego JP, Halpern AC. Congenital Melanocytic Nevi: Treatment Modalities and Management Options. Semin Cutan Med Surg. 2007;26:231-40.

64. Hernández A, Torrelo A. Recent Data on the Risk of Malignancy in Congenital Melanocytic Nevi: The Continuing Debate on Treatment. Actas Dermosifiliogr. 2008;99:185-9.

65. Krengel S, Marghoob AA.Current Management Approaches for Congenital Melanocytic Nevi. Dermatol Clin. 2012;30:377-87.

66. Paradela S, Fernández-Torres R, Fonseca E. Controversias en el nevus congénito. Actas Dermosifiliogr. 2009;100:548-61.

67. Alikhan A, Ibrahimi OA, Eisen DB. Congenital melanocytic nevi: Where are we now? Part I. Clinical presentation, epidemiology, pathogenesis, histology, malignant transformation, and neurocutaneous melanosis. J Am Acad Dermatol. 2012;67:495.e1-17.

68. Kovalyshyn I, Braun R, Marghoob A. Congenital melanocytic naevi. Australas J Dermatol. 2009;50:231-40

69. Krengel S, Hauschild A, Schäfer T. Melanoma risk in congenital melanocytic naevi: a systematic review. Br J Dermatol. 2006;155:1-8.

70. DeDavid M, Orlow SJ, Provost N, Marghoob AA, Rao BK, Huang CL, et al. A study of large congenital melanocytic nevi and associated malignant melanomas: review of cases in the New York University Registry and the world literature. J Am Acad Dermatol. 1997;36:409-16.

71. Ibrahimi OA, Alikhan A, Eisen DB. Congenital melanocytic nevi: Where are we now? Part II. Treatment options and approach to treatment. J Am Acad Dermatol. $2012 ; 67: 515 . e 1-13$

72. Vourc'h-Jourdain M, Martin L, Barbarot S; aRED. Large congenital melanocytic nevi: Therapeutic management and melanoma risk. A systematic review. J Am Acad Dermatol. 2013;68:493-8.e1-14.

73. Slutsky JB, Barr JM, Femia AN, Marghoob AA. Large Congenital Melanocytic Nevi: Associated Risks and Management Considerations. Semin Cutan Med Surg. 2010;29:79-84.

74. Watt AJ, Kotsis SV, Chung KC. Risk of melanoma arising in large congenital melanocytic nevi: a systematic review. Plast Reconstr Surg. 2004;113:1968-74.

75. Zayour M, Lazova R. Congenital Melanocytic Nevi. Clin Lab Med. 2011;31:267-80

76. Lyon VB .Congenital Melanocytic Nevi. Pediatr Clin North Am. 2010;57:1155-76.

77. Price HN, Schaffer JV. Congenital melanocytic nevi-when to worry and how to treat: Facts and controversies. Clin Dermatol. 2010;28:293-302.

78. Arneja JS, Gosain AK. Giant Congenital Melanocytic Nevi. Plast Reconstr Surg. 2009;124:1e-13e. 
79. Marghoob AA, Dusza S, Oliveria S, Halpern AC. Number of satellite nevi as a correlate for neurocutaneous melanocytosis in patients with large congenital melanocytic nevi. Arch Dermatol. 2004;140:171-5.

80. Balch CM, Gershenwald JE, Soong SJ, Thompson JF, Atkins MB, Byrd DR, et al. Final version of 2009 AJCC melanoma staging and classification. J Clin Oncol. 2009;27:6199-206.

81. Bichakjian CK, Halpern AC, Johnson TM, Foote Hood A, Grichnik JM, Swetter SM, et al; American Academy of Dermatology. Guidelines of care for the management of primary cutaneous melanoma. American Academy of Dermatology. J Am Acad Dermatol. 2011;65:1032-47.

82. Fong ZV, Tanabe KK. Comparison of melanoma guidelines in the U.S.A., Canada, Europe, Australia and New Zealand: a critical appraisal and comprehensive review. Br J Dermatol. 2014;170:20-30.

83. Pflugfelder A, Kochs C, Blum A, Capellaro M, Czeschik C, Dettenborn T, et al. Malignant melanoma S3-guideline "diagnosis, therapy and follow-up of melanoma”. J Dtsch Dermatol Ges. 2013:11:1-116, 1-126.

84. Bassères N, Grob JJ, Richard MA, Thirion X, Zarour H, Noe C, et al. Costeffectiveness of surveillance of stage I melanoma. A retrospective appraisal based on a 10-year experience in a dermatology department in France. Dermatology. 1995;191:199-203

85. Francken $A B$, Bastiaannet $E$, Hoekstra HJ. Follow-up in patients with localised primary cutaneous melanoma. Lancet Oncol. 2005;6:608-21.

86. Moore Dalal K, Zhou Q, Panageas KS, Brady MS, Jaques DP, Coit DG. Methods of detection of first recurrence in patients with stage $\mathrm{I} / \mathrm{ll}$ primary cutaneous melanoma after sentinel lymph node biopsy. Ann Surg Oncol. 2008;15:2206-14.

87. Pollitt RA, Geller AC, Brooks DR, Johnson TM, Park ER, Swetter SM. Efficacy of skin self-examination practices for early melanoma detection. Cancer Epidemiol Biomarkers Prev. 2009;18:3018-23.

88. Mocellin S, Zavagno G, Nitti D. The prognostic value of serum S100B in patients with cutaneous melanoma: a meta-analysis. Int J Cancer. 2008;123:2370-6.

89. Tarhini AA, Stuckert J, Lee S, Sander C, Kirkwood JM. Prognostic significance of serum $\mathrm{S} 100 \mathrm{~B}$ protein in high-risk surgically resected melanoma patients participating in Intergroup Trial ECOG 1694. J Clin Oncol. 2009;27:38-44.

90. Brown RE, Stromberg AJ, Hagendoorn LJ, Hulsewede DY, Ross MI, Noyes RD, et al. Surveillance after surgical treatment of melanoma: futility of routine chest radiography. Surgery. 2010;148:711-6.

91. Leiter U, Marghoob AA, Lasithiotakis K, Eigentler TK, Meier F, Meisner C, et al. Costs of the detection of metastases and follow-up examinations in cutaneous melanoma. Melanoma Res. 2009;19:50-7.

92. Morton RL, Craig JC, Thompson JF. The role of surveillance chest $\mathrm{X}$-rays in the follow-up of high-risk melanoma patients. Ann Surg Oncol. 2009;16:571-7.

93. Tsao H, Feldman M, Fullerton JE, Sober AJ, Rosenthal D, Goggins W. Early detection of asymptomatic pulmonary melanoma metastases by routine chest radiographs is not associated with improved survival. Arch Dermatol. 2004;140:67-70.

94. Bafounta ML, Beauchet A, Chagnon S, Saiag P. Ultrasonogra $\neg$ phy or palpation for detection of melanoma nodal invasion: a meta-analysis. Lancet Oncol. 2004:5:673-80.

95. Blum A, Schlagenhauff B, Stroebel W, Breuninger H, Rassner G, Garbe C Ultrasound examination of regional lymph nodes significantly improves early detection of locoregional metastases during the follow-up of patients with cutaneous melanoma: results of a prospective study of 1288 patients. Cancer. 2000;88:2534-9.

96. Machet L, Nemeth-Normand F, Giraudeau B, Perrinaud A, Tiguemounine J, Ayoub $J$, et al. Is ultrasound lymph node examination superior to clinical examination in melanoma follow-up? A monocentre cohort study of 373 patients. Br J Dermatol. 2005; 152:66-70.

97. Rossi CR, Seno A, Vecchiato A, Foletto M, Tregnaghi A, De Candia A, et al. The impact of ultrasound scanning in the staging and follow-up of patients with clinical stage I cutaneous melanoma. Eur J Cancer. 1997;33:200-3.

98. Brenner DJ, Hall EJ. Computed tomography- an increasing source of radiation exposure. N Engl J Med. 2007;357:2277-84.

99. Clark PB, Soo V, Kraas J, Shen P, Levine EA. Futility of fluorodeoxyglucose $F$ 18 positron emission tomography in initial evaluation of patients with T2 to T4 melanoma. Arch Surg. 2006;141:284-8.
MAILING ADDRESS:

Luiz Guilherme Martins Castro

Rua Mato Grosso 306 cj 604

01239040 - São Paulo - SP.

Brazil

Email:.lgmc@dermaclinica.com.br

How to cite this article: Castro LGM, Bakos RM, Duprat J, Bittencourt FV, Di Giacomo THB, Serpa SS, Messina MCL, Loureiro WR, Macarenco RS, Stolf HO, Gontijo G. Brazilian guidelines for diagnosis, treatment and follow-up of primary cutaneous melanoma - Part II. An Bras Dermatol. 2016;91(1):49-58. 